\title{
Screening and Preliminary Identification of Medicinal Plants Endophytic Actinomycetes Used for Inhibiting Penicillin-Resistant Staphylococcus aureus
}

\author{
Xiumin Zhang, Kai Ren \& Liping Zhang \\ College of Life Sciences, Hebei University \\ Key Laboratory of Microbial Diversity Research and Application of Hebei Province \\ Baoding 071002, China \\ E-mail: zhxiumin1106@126.com
}

Received: February 13, 2012

Accepted: February 25, $2012 \quad$ Published: April 1, 2012

doi:10.5539/ijb.v4n2p119

URL: http://dx.doi.org/10.5539/ijb.v4n2p119

This research was financially supported by National Science Foundation Project of Hebei Province (Grant No.C2010000260) and Doctor Fund Project of Hebei University (Grant No.2007-711).

\begin{abstract}
65 strains of endophytic actinomycetes were isolated from Achyranthes bidentata, Paeonia lactiflora, Radix Platycodi and Artemisiae argyi. Active strains of inhibiting penicillin-resistant staphylococcus aureus were screened from these strains and some were identified preliminarily. The results showed that 12 strains among these 65 strains of endophytic actinomycetes were able to suppress penicillin-resistant staphylococcus aureus. Through the observation on morphology of mycelium and phylogenetic analysis of $16 \mathrm{~S}$ rDNA, a strain belongs to the genus Glycomyces and most other as the genus Streptomyces.
\end{abstract}

Keywords: Medicinal plants, Endophytic actinomycetes, Penicillin-resistant Staphylococcus aureus, antagonistic activity, Screening, Identification

\section{Introduction}

Since Fleming discovered the first antibiotic-penicillin in 1929, the discovery and application of antibiotics successfully prevent and treat various diseases infected by microbes. However, due to the long-term and extensive use of antibiotics, a large number of drug-resistant strains emerged in clinic. According to reports, the average chance of infection by drug-resistant Mycobacterium tuberculosis has reached $10.2 \%$, and Mycobacterium tuberculosis and Staphylococcus aureus as a common pathogenic bacteria are prone to mutation and drug resistance (Monaghan, et al., 2006).The enhancement of bacterial resistance to drugs caused great difficulties to clinical anti-infective therapy, hence it was concerned widely. The people are constantly trying to find new antimicrobial substances from different organisms to resist the various germs which can threat to human life and health.

Actinomycetes is the main source of antibiotics and endophytic actinomycetes isolated from medicinal plants has considerable development potential. From the present findings, some new actinomycetes from tissue of medicinal plants have been founded constantly (Kudo, et al., 1998; Chen, et al., 2009; Qin, et al., 2008, 2010). Moreover, most endophytic actinomycetes of medicinal plants can produce important compounds and some of them are new chemical structure (Caruso, et al., 2000; Ezra, et al., 2004; Liu, et al., 2007).

The purpose of this study is to isolate endophytic actinomycetes from the medicinal plants and to screen antagonistic strains of drug-resistant Staphylococcus aureus among the isolating strains. 


\section{Materials and Methods}

\subsection{Materials}

\subsubsection{Source of medicinal plants}

Achyranthes bidentata, Paeonia lactiflora, Radix Platycodi, Artemisiae argyi were collected from Chinese herbal medicine planting base of Anguo, Baoding City, Hebei Province, China.

\subsubsection{Pathogenic instructions bacteria}

Penicillin-resistant staphylococcus aureus HBUY100301 was reserved by this laboratory.

\subsection{Methods}

\subsubsection{Isolation and cultivation of endophytic actinomycetes}

The root tissue of medicinal plants was washed by tap water and surface sterilized with $75 \%$ alcohol for $5 \sim 10 \mathrm{~min}$ and $0.1 \% \mathrm{HgCl} 2$ for 2 5min, finally washed by sterile water for 4 times before being ground and spread onto S Agar (Lechevalier, et al., 1983), Starch-Casein Agar (Ku"ster, et al. 1964) and Flour yeast-extract

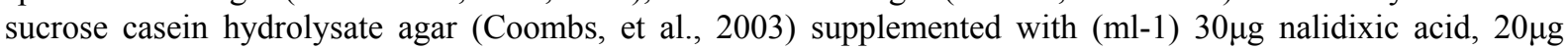
ketoconazole and $50 \mu \mathrm{g}$ cycloheximide. After incubation at $28^{\circ} \mathrm{C}$ for $2-4$ weeks, the strains were isolated and purified on ISP2 agar (Shirling \& Gottlieb, 1966).The pure culture was maintained as a suspension in $30 \%$ glycerol at $-80^{\circ} \mathrm{C}$ and lyophilized cells for long-term preservation.

\subsubsection{Screening of antagonistic strains}

\subsubsection{Preparation of inoculum and fermentation}

Spore suspension was prepared in distilled water from culture grown on $\mathrm{S}$ medium at $28^{\circ} \mathrm{C}$ for 7 days. The suspension was added to ISP-2 broth in each $500 \mathrm{ml}$ Erlenmeyer flask at 10\% inoculum rate in $100 \mathrm{ml}$ liquid medium. Cultures were kept on a shaker at $180 \mathrm{r} / \mathrm{min}$ at $28^{\circ} \mathrm{C}$ for 7 days. The fermentation liquid were extracted with isopyknic methyl alcohol and centrifugation at $5000 \mathrm{r} / \mathrm{min}$ for $20 \mathrm{~min}$. Extracting solution was concentrated under vacuum and then preserved at $-20^{\circ} \mathrm{C}$.

\subsubsection{Antagonistic-activity assay}

Two $8 \mathrm{~mm}$ discs of sterile paper was soaked in extracting solution above. The air-dried discs were palced on a NA plate which was inoculated penicillin-resistant staphylococcus aureus. After incubation at $28^{\circ} \mathrm{C}$ for $24 \mathrm{~h}$, the result with or without inhibition zone was observed. Each treatment consisted of three replicates. The experiment was repeated twice.

\subsubsection{Identification of active strains}

\subsubsection{Observation of morphological characteristics}

Strain was inoculated on ISP-2 agar and coverslip was inserted into medium, cultivated at $28^{\circ} \mathrm{C}$ for 5 days. Then the coverslip was placed under the light microscope to observe morphological characteristics of Mycelium.

\subsubsection{Phylogenetic analysis of $16 \mathrm{~S}$ rDNA}

(1) Extration of genomic DNA

Genomic DNA was extracted by the method of Fred (Fred at al., 1996).

(2) PCR amplification of 16S rDNA sequence

The 16S rDNA sequence was amplified using 27f (E.coli 8-27 bases: 5'-GAG TTT GAT CCT GGC TCA G-3')

and 1525r (E.coli 1525-1545 bp: 5'-AGA AAG GAG GTG TAC CAGCC-3') as primers. Amplification was carried out in a TaKaRa thermal cycler, with an initial incubation step at $94^{\circ} \mathrm{C}$ for $4 \mathrm{~min}, 30$ cycles of $94^{\circ} \mathrm{C}$ for $0.5 \mathrm{~min}, 55^{\circ} \mathrm{C}$ for $0.5 \mathrm{~min}$ and $72{ }^{\circ} \mathrm{C}$ for $1.5 \mathrm{~min}$ and a final extension step at $72^{\circ} \mathrm{C}$ for $10 \mathrm{~min}$, and PCR products were sequenced by Beijing Sinogene Biotech Co.Ltd.

(3) Construction of phylogenetic tree

The obtained 16S rDNA sequences was undertaken homology comparison with the known sequences of

Genbank database using BLAST method. Multiple alignment of the sequences obtained from GenBank was performed using CLUSTAL W (Thompson, et al., 1994). Phylogenetic trees were constructed with MEGA version 5.0 (Tamura, et al., 2011) using the neighbour-joining method (Saitou \& Nei, 1987) and the reliability of the tree topology was evaluated by bootstrap analysis with 1000 resamplings (Felsenstein, 1985). 


\section{Results and Analysis}

\subsection{Isolation of endophytic actinomycetes}

65 strains of endophytic actinomycetes were isolated from Achyranthes bidentata, Paeonia lactiflora, Radix Platycodi and Artemisiae argyi.

\subsection{Screening of antagonistic strains}

12 among 65 strains of endophytic actinomycetes were able to suppress penicillin-resistant staphylococcus aureus. The Numbers of strains is as table 1 and some photos of bacteriostasis are as (figure 1)

\subsection{Identification of active strains}

\subsubsection{Morphological characteristics}

The result of observation of morphological characteristics showed most active strains had typical spiral spore chain (Figure 1, A) and these feature consistented with the genus Streptomyces, in addition to some strains (Figure 1, B). 16S rDNA phylogenetic analysis of part of the representative strains were carried o further determine their taxonomic status.

\subsubsection{Phylogenetic analysis of 16S rDNA}

Almost-complete 16S rRNA gene sequence of each strain was preliminarily compared with 16S rRNA gene sequences in the GenBank database. The results indicated that strain SC-N040902, S-BS033004 and SC-JG031807 belonged to Streptomyces, and strain F22 belonged to Glycomyces. The accession numbers in GenBank of these 4 strains were JN408737, JN408735, JN408741 and JN408754, respectively. The result of the phylogenetic analysis indicated that the closest phylogenetic neighbours of strain SC-JG031807 were $S$.

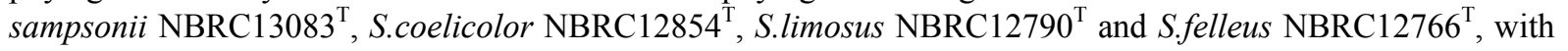
16S rRNA gene sequence similarity values of 99.9(Figure 3.); of strain S-BS033004 were S.anulatus NBRC13369 ${ }^{\mathrm{T}}$, S.praecox $\mathrm{NBRC} 3073^{\mathrm{T}}$, S.rubiginosohelvolus $\mathrm{NBRC}^{2} 212^{\mathrm{T}}$, S.mediolani NBRC15427 ${ }^{\mathrm{T}}$, S.griseinus NBRC12869 ${ }^{\mathrm{T}}$, and S. pluricolorescens NBRC12808 ${ }^{\mathrm{T}}$, with $16 \mathrm{~S}$ rRNA gene sequence similarity values of $99.9 \%$ (Figure 3.); of strains SC-N040902 were $S$. cavourensis subsp. washingtonensis NRRLB-8030 ${ }^{\mathrm{T}}$, with 16S rRNA gene sequence similarity values of 99.8(Figure 3.); of strain IF22 were Glycomyces sambucus DSM $45047^{\mathrm{T}}$ and Glycomyces scopariae DSM44968 ${ }^{\mathrm{T}}$, with $16 \mathrm{~S}$ rRNA gene sequence similarity values of 98.1\%(Figure 4.).

\section{Discussions}

With the increasing number of antibiotic applications, bacterial resistance has become a serious problem faced by the world anti-infective therapeutic area. In the present study, 12 strains of endophytic actinomycetes which could inhibit penicillin-resistant staphylococcus aureus were successfully isolated from Achyranthes bidentata, Paeonia lactiflora, Radix Platycodi, Artemisiae argyi. The results showed endophytic actinomycetes of medicinal plants are important resource and finding some new compounds to suppress drug-resistant strains from secondary metabolites of medicinal plants endophytic actinomycetes is expected to become an effective way to resolve the above problem.

In addition, the preliminary identification of some active strains in this study showed that the most belonged to the genus Streptomyces. This result is consistent with previous report which Streptomyces is the most important strains of antibiotic production; from another perspective, the rapid growth of the Streptomyces are likely to affect the separation of other actinomycetes. Therefore, the selectivity of isolation and culture methods to the slower growth of endogenous actinomycetes should be increased.

\section{References}

Caruso, M., Colombo, A. L., Crespi, P. N., et al. (2000). Studies on a strain of Kitasatospora sp. paclitaxol producer. Ann. Microbiol, 50, 89-102.

Chen, H. H., Qin, S., Li, J., et al. (2009). Pseudonocardia endophytica sp. nov., isolated from the pharmaceutical plant Lobelia clavata. Int J Syst Evol Microbiol, 59, 559-563. http://dx.doi.org/10.1099/ijs.0.64740-0

Coombs, J. T., \& Franco, C. M. (2003). Isolation and Identification of Actinobacteria from Surface-Sterilized Wheat Roots. Appl Environ Microbiol, 69(9), 5603-5608. http://dx.doi.org/10.1128/AEM.69.9.5603-5608.2003

Ezra, D., Castillo, U. F., Strobel, G. A., et al. (2004). Coronamycins, peptide antibiotic sproduced by a verticillate Streptomyces sp. (MSU-2110) endophytic on Monstera sp. Microbiology, 150, 785-793. http://dx.doi.org/10.1099/mic.0.26645-0 
Felsenstein, J. (1985). Confidence limits on phylogenies: an approach using the bootstrap. Evolution, 39, 783-791. http://dx.doi.org/10.2307/2408678

Fred, A. R., Rainey, N. W., Kroppenstedt, R. M., et al. (1996). The Genus Nocardiopsis Represents a Phylogenetically Coherent Taxon and a Distinct Actinomycete Lineage: Proposal of Nocardiopsaceae fam.nov. Int J Syst. Evol Microbiol, 46, 1088-1092. http://dx.doi.org/10.1099/00207713-46-4-1088

Ku"ster, E., \& Williams, S. T. (1964). Selection of media for the isolation of streptomycetes: starch casein medium. Nature, 202, 928-929.

Kudo, T., Matsushima, K., Sasaki., et al. (1998). Description of four new species of the genus Kineosporia: Kineosporia succinea sp.nov, Kineosporia milkurie sp.nov.and Kineosporia rhamnosa sp.nov.,isolated from plant samples and amended description the genus Kineosporia. Int $J$ Syst Bacteriol, 48, 1245-1255. http://dx.doi.org/10.1099/00207713-48-4-1245

Lechevalier, M. P., \& Horriere, B. D. (1983). Physiology, chemistry, serology, and infectivity of two Frankia isolates from Alnusincana sub sp. Canadian Journal of Botany, 61(11), 2826-2833. http://dx.doi.org/10.1139/b83-314

Liu, N., Zhang, H., Zheng, W., et al. (2007). Bioactivity of endophytic actinomycetes from medicinal plants and secondary metabolites from strain D62. Acta Microbiologica Sinica, 47(5), 823-827. http://www.ncbi.nlm.nih.gov/pubmed/18062256

Monaghan, R. L., \& Barrett, J. F. (2006). Antibacterial drug discovery-then, now and the genomics future. Bichenmical Pharmacology, 7, 901-909. http://dx.doi.org/10.1016/j.bcp.2005.11.023

Qin, S., Chen, H. H., Klenk, H. P., et al. (2010). Saccharopolyspora gloriosae sp. nov., an endophytic actinomycete isolated from the stem of Gloriosa superba L. Int J Syst Evol Microbiol, 60, 1147-1151. http://dx.doi.org/10.1099/ijs.0.015792-0

Qin, S., Wang, H. B., Chen, H. H., et al. (2008). Glycomycese ndophyticus sp. nov., an endophytic actinomycete isolated from the root of Carex baccans Nees. Int $J$ Syst Evol Microbiol, 58, 2525-2528. http://dx.doi.org/10.1099/ijs.0.2008/000398-0

Saitou, N., \& Nei, M. (1987). The neighbor-joining method: a new method for reconstructing phylogenetic trees. Mol Biol Evol, 4, 406-425. http://www.ncbi.nlm.nih.gov/pubmed/3447015

Shirling, E. B., \& Gottlieb, D. (1966). Methods for characterization of Streptomyces species. Int J Syst Bacteriol, 16, 313-340. http://dx.doi.org/10.1099/00207713-16-3-313

Tamura, K., Peterson, D., Peterson, N. S., et al. (2011). MEGA5: Molecular Evolutionary Genetics Analysis using Maximum Likelihood, Evolutionary Distance, and Maximum Parsimony Methods. Molecular Biology and Evolution, 28(10), 2731-2739. http://dx.doi.org/10.1093/molbev/msr121

Thompson, J. D., Higgins, D. G., \& Gibson, T. J. (1994). CLUSTAL W: improving the sensitivity of progressive multiple sequence alignment through sequence weighting, position-specific gap penalties and weight matrix choice. Nucleic Acids Research, 22, 4673-4680. http://dx.doi.org/ 10.1093/nar/22.22.4673

Table 1. The numbers of endophytic actinomycetes wirh antagonistic activity and their source

\begin{tabular}{|c|c|}
\hline Materials & Numbers of strains \\
\hline Achyranthes bidentata & F-N33001. F-N33002. F-N33003. F-N33004. F-N3010. \\
& SC-N40902. SC-N40903 \\
\hline Paeonia lactiflora & S-BS033004. F-BS040902 \\
\hline Artemisiae argyi & IF22. IXS5 \\
\hline Radix Platycodi & SC-JG1807 \\
\hline
\end{tabular}



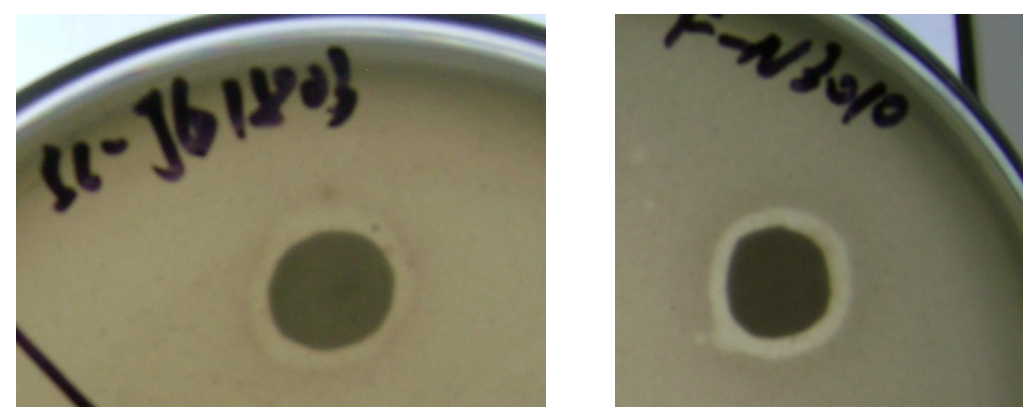

Figure 1. The antibacterial photos of strain SC-JG1807 and strain F-N3010
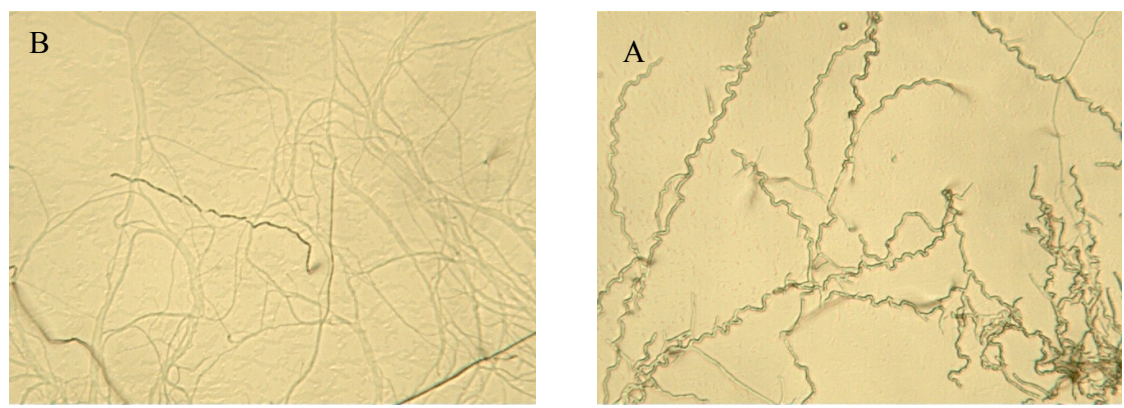

Figure 2. The morphological characteristics of Mycelium stains F-N3010 (A) and strain (B) (400×)

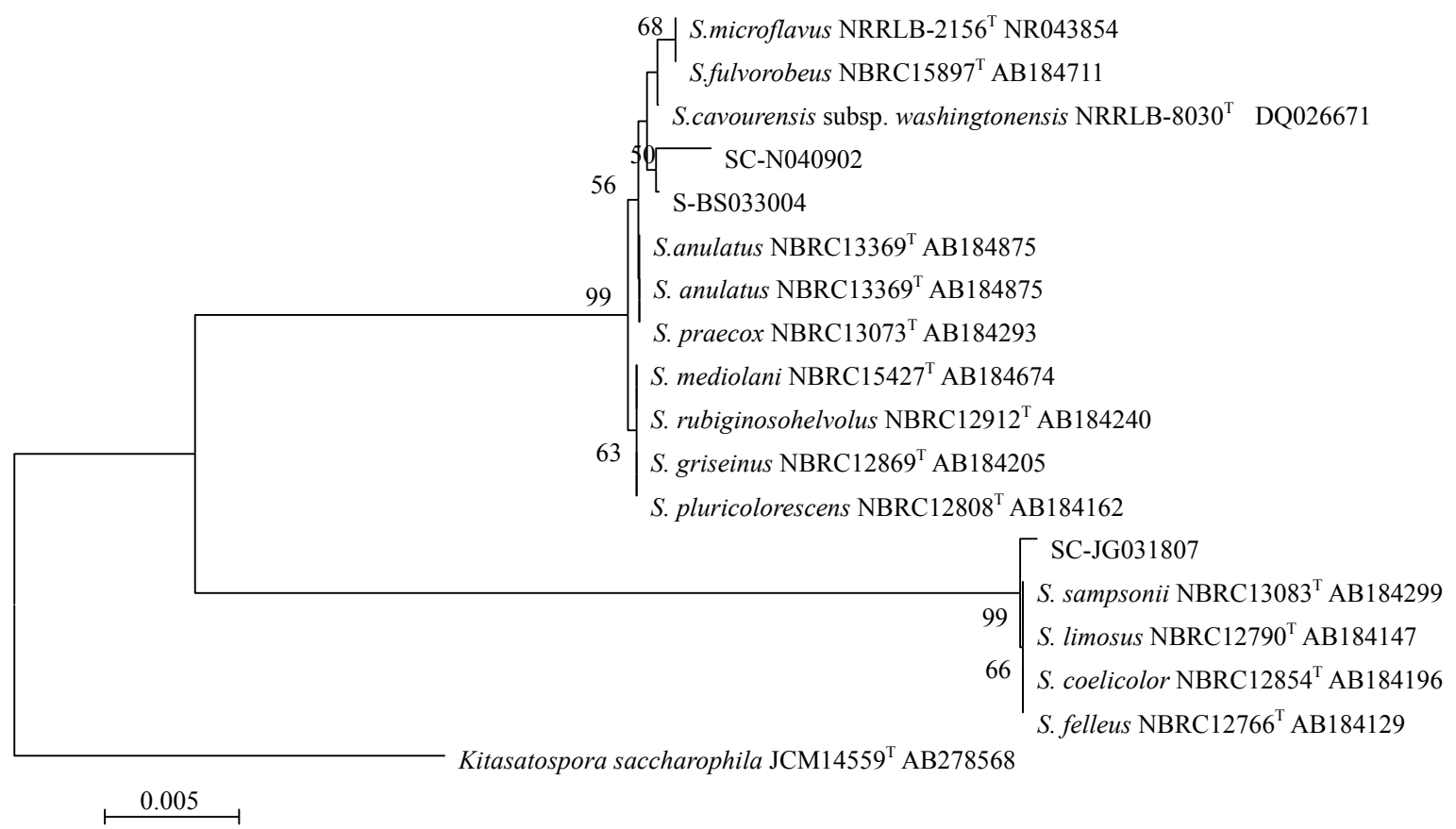

Figure 3. Neighbour-joing tree based on 16S rDNA sequences between strain SC-N040902, S-BS033004, SC-JG031807 and representive strains of Streptomyces 


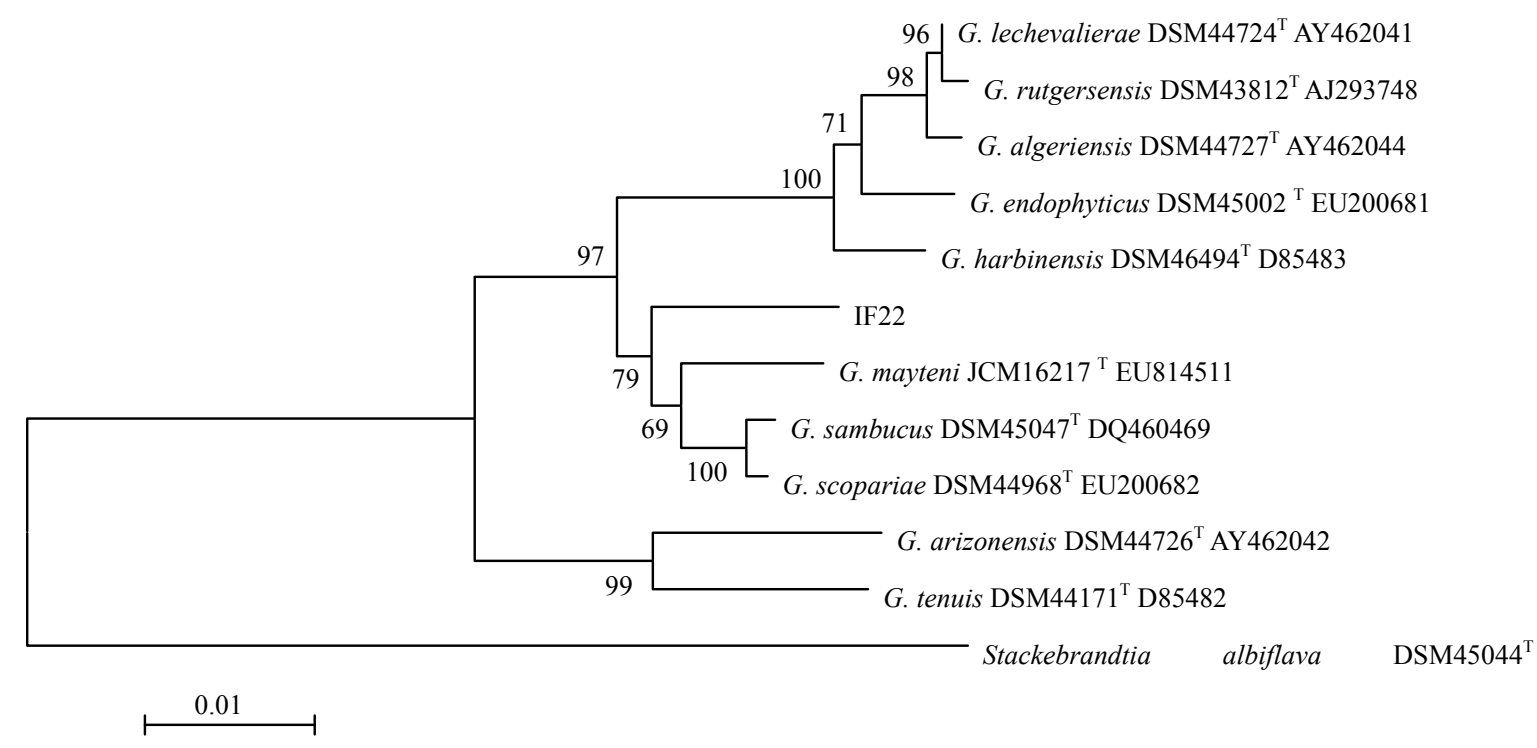

Figure 4. Neighbour-joing tree based on 16S rDNA sequences between strain IF22 and representive strains of Glycomyces 